\title{
Protective Factors for Teacher Resilience in Elementary Special Educations
}

\author{
Zarina $\mathrm{Akbar}^{1}$, Mauna $^{2}$ \\ Faculty of Psychology Universitas Negeri Jakarta, Jalan Rawamangun Muka ${ }^{1,2}$ \\ \{zarina_akbar@unj.ac.id ${ }^{1}$, mauna@unj.ac.id²
}

\begin{abstract}
This research aims to examine the protective factors associated with resiliency among teachers in elementary special educations. Psychological resilience is maintained to be fundamental for teachers because they are constantly exposed to various stressors that they only have a little control, such as a high workload, conflicting demands, lack of recognition, poor physical environment and student's misbehavior. Teacher resilience is very important in enabling the teacher to respond positively to the challenging circumstances. Related to this research, some participants have completed the survey developed to represent the measurement of some protective factors, namely the selfcompassion and self-esteem. Regression analysis was used to determine the association among protective factors for the resilience. The results indicate that the two protective factors contribute to teacher resilience. It can be concluded that supporting the teacher resilience is a promising practice that is important to the educational planning efforts especially in elementary special educations.
\end{abstract}

Keywords: Teacher, Resiliency, Protective Factors, Elementary School, Special Educations

\section{Introduction}

Teacher resilience is a field research that emerges and partly because of the complex nature of resilience. There are various ways of resilience in the teaching context that have been defined in the literature. For example, teacher resilience has been described as the quality of teacher who remains committed to teaching or the development process that occurs from time to time which involves the ability to adapt to various situations and improve one's competence in the face of adverse conditions [1]. Teacher resilience plays a role in enabling the teachers to respond positively to challenging situations they might face during their career.

Resilience is defined as the ability to bounce back from stress, pressure or disturbance due to a pattern of change, and an individual's ability to adapt to pressure [2]. Resilience is a number of ways used by teachers in maintaining the continuity of their tasks [3].

Teachers are also expected to have the ability to manage emotions that must be tailored to the needs and characteristics of their students. The thing that teachers can do in overcoming any less pleasant emotions is to have a respectful attitude or compassion towards themselves. This attitude is called self-compassion. Self-compassion is derived from the assumption that every human being is meaningful and valuable, regardless of their physical characteristics and 
achievements [4]. Self-compassion is a willingness to be touched by and aware when experiencing a suffering and to not avoid the suffering [5].

Another factor affecting self-resilience is the self-esteem. The researches on self-esteem that have been developed stated that self-worth (self-esteem) is a positive or negative evaluation of oneself. Self-esteem is about how someone views or values himself/herself. Selfesteem can also relate to specific dimensions, such as academic ability, social skill, physical appearance, or collective self-worth, which is an evaluation of the value of a group where a person is in. Self-esteem is considered to be one of the important aspects in the formation of one's personality [6]. Based on the explanation above, the researcher is interested in knowing the influence of self-compassion and self-esteem towards resilience possessed by elementary special education teachers.

\section{Methodology}

This research uses a quantitative approach method by utilizing the regression analysis approach. The population in this study is Elementary Special Education teachers in Jakarta. The sampling technique used in this study is the non-probability sampling. The technique used is the purposive sampling. The number of samples in this study is 100 people. In this study, data collection is done by using a questionnaire. For resilience variables, the questionnaire uses a measurement tool based on the Grotberg theory which consists of 55 statements. The self-compassion variable uses the Self Compassion Scale (SCS) measurement tool created by Kristin Neff which consists of 26 statements. Whereas the self-esteem instrument used in this study is the Rosenberg Self- Esteem Scale made by Rosenberg which consists of 10 statements.

\section{Result}

The main text should be written using Times New Roman, 10pt, fully justified. Italics can be used for emphasis and bold typeset should be avoided.

Table 1. Score of Self-Compassion

\begin{tabular}{ccc}
\hline Self-Compassion & N & Percentages \\
\hline Low & 64 & $64 \%$ \\
High & 36 & $36 \%$ \\
\hline
\end{tabular}

Table 2. Score of Self-Esteem

\begin{tabular}{ccc}
\hline Self-Esteem & N & Percentages \\
\hline Low & 57 & $57 \%$ \\
High & 43 & $43 \%$ \\
\hline
\end{tabular}

Table 3. Score of Resilience

\begin{tabular}{ccc}
\hline Resilience & $\mathbf{N}$ & Percentages \\
\hline Low & 50 & $50 \%$ \\
High & 50 & $50 \%$ \\
\hline
\end{tabular}


Statistical analysis in this research used the multiple regression in order to explore more of the relationships between self-compassion and self-esteem to the resilience in elementary special educations.

Table 4. Analysis of Multiple Regression

\begin{tabular}{llll}
\hline & df & F & Sig \\
\hline Regression & 2 & 23.963 & 0.000 \\
Residual & 97 & & \\
\hline
\end{tabular}

According to Table 4 , it can be seen that $p=0.000$ (significance). It means that selfcompassion and self-esteem are related to the resilience in elementary special educations in Jakarta.

Table 5. Model Summary

\begin{tabular}{lll}
\hline $\mathbf{R}$ & R Square & Adjusted R Square \\
\hline $\mathbf{0 . 5 7 5}$ & 0.331 & 0.317 \\
\hline
\end{tabular}

According to the statistical analytic in Table 5, it can be seen that self-compassion and self-esteem contribute $33.1 \%$ to resilience in the elementary special educations. While the other $66.9 \%$ is influenced by factors other than the self-compassion and self-esteem.

\section{Discussion}

Special education teachers have a heavy work demands in different contexts. Such teachers generally have a greater responsibility and duty to educate their students than the publicschool teachers in general. They have their own challenges with their students who have problems in emotional and behavioral matters since it is a problem owned by students with special needs [7]. Their responsibilities as educators are causing them to have more challenging basic tasks in educating their students to develop in their social environment.

Special education teachers should also have the special patience to make the children (students) able to be patient sitting in the classroom longer and listen to the material delivered because their students have more physical movements such as running, throwing things, and even injuring themselves. It requires the teachers to be patient in the work they do. Therefore, a teacher should have a mature, strong personality, and the ability to deal with the problems at hand. The ability to defend yourself from stresses is called resilience. According to Lacoviello and Charney [8], resilience is a part of positive psychology. The end result expected from resilience is to form individuals to redefine the quality of life, and direct them to a positive lifestyle. The expected end result of resilience is to form individuals that are able to deal with stresses.

Resilience is defined as the ability to bounce back from stress, pressure or disturbance due to a pattern of change, and an individual's ability to adapt to pressure [2]. Resilience is a number of ways used by teachers in maintaining the continuity of their tasks [3]. Resilience has an important role in education, since it is unrealistic to expect the students to be resilient if their educators do not have the resilience themselves [9]. Resilience is not innate, otherwise, it is a relatively developing and dynamic formation that resulted from the positive adaptation and psychological development of individuals in challenging circumstances [10].

Self-compassion arises from the assumption that every man is meaningful and valuable, regardless of their physical characteristics and achievements [4]. According to Germer [5], self-compassion is a willingness to be touched by and aware when experiencing a suffering and to not avoid the suffering. Another definition put forward by Neff and Faso [11] added 
that self-compassion is a process of uncritical understanding of suffering, failure or inability by understanding that these three things are part of the experience that a human being would feel in general. Individuals who have a high self-compassion have the characteristic of being able to accept their own strengths and weaknesses, mistakes or failures as a general thing that is also experienced by others, and have an awareness of the connection between everything that happened [12].

The study conducted by Bluth, Mullarkey, and Lathren [13] found a relationship between resilience and self-compassion. Self-compassion is very important for our lives, to help us struggling in life and stop blaming ourselves for the things that cannot be controlled. It can provide the social support and encourage the interpersonal trust [14]. As an individual who works as a teacher in a public-school, particularly in special education, it is not easy to deal with the demands and pressures coming from schools and families and the surrounding environment. Another factor that affects self-resilience is the self-esteem. Self-esteem is considered to be one of the important aspects in the formation of one's personality [15]. If a person cannot appreciate himself, it will be difficult for him/her to be able to appreciate the people around him/her. Thus, self-esteem is an important element for the formation of one's self-concept and it will have a broad impact on attitudes and behavior. Those who have low self-esteem are thought to have a tendency of having depression, drugs, and close to violence [16].

Self-esteem assists in increasing one's initiative, resilience and feeling of satisfaction. It appears that high self-esteem reflects positive personal conditions that lead to a good attitude in interacting with others. Someone with a high self-esteem is said to have a high resilience, namely the ability to rise again, by overcoming the pressure that he/she experienced. Even though someone has a high self-esteem, someday he/she will experience a failure or disappointment that might make the self-esteem decrease. This condition is known as the threatened self-esteem. In these conditions, the self-esteem can decrease. This threat to selfesteem then creates a reaction to self-defense that can be done by putting others down and exaggerating their superiority over others [17]. One of the possible factors that can influence the resilience is self-esteem. Reivich and Shatte [18] explained that resilience is a combination of the three factors of I Am, I Have, I Can. This reaction is actually someone's effort to maintain self-esteem from the threat or various things that can reduce the self-esteem. A situation where someone tries to maintain the self-esteem is known as self-esteem maintenance [19]. Those who feel their self-esteem is threatened will confront other people's success as something that will threaten their existence or worthiness. This feeling of being threatened will cause a reaction that drive someone to overthrow others, whether by putting others down or even by using violence.

\section{Conclusion}

Based on the calculation results, it can be concluded that there is an influence between self-compassion and self-esteem on resilience in public special school teachers in Jakarta. According to the analysis of score categorization, it can be seen that the public special school teachers have a low level of self-compassion and self-esteem so that an optimization or improvement is needed, for example by giving a psychological training program.

\section{References}


[1] Beltman, S., Mansfield, C. F., \& Price, A. (2011). Thriving not just surviving: A review of research on teacher resilience. Educational Research Review, 6(3), 185-207. DOI: 10.1016/j.edurev.2011.09.001.

[2] Colvin, H. M., Taylor, R. M. (2012). Building a resilient workforce. Washington DC: National academies press.

[3] Gu, Q., Day, C. (2007). Teachers resilience: A necessary condition for effectiveness. Journal Teaching and Teacher Education, 1302-1317.

[4] Teleb, A. A. \& Awamleh, A. A. A. (2013). The relationship between self compassion and emotional intelligence for university students. Current Research in Psychology, 4(2), 20-27. https://doi.org/10.3844/crpsp.2013.20.27

[5] Germer, K.C. (2009). The mindful path to self compassion: Freeing yourself from destructive thoughts and emotions. New York : The Guilford Press.

[6] Harris, M. A., \& Orth, U. (2019). The link between self-esteem and social relationships: A meta-analysis of longitudinal studies. Journal of Personality and Social Psychology. Advance online publication. http://dx.doi.org/10.1037/pspp0000265.

[7] Mackenzie, S. (2012). I can't imagine doing anything else: Why do teachers of children with SEN remain in the profession? Resilience, rewards and realism over time. Journal of Research in Special Educational Needs, 12(3), 151-161.

[8] Lacoviello, B., \& Charney, D. (2014). Psychosocial facets of resilience: implications for preventing posttrauma psychopathology, treating trauma survivors, and enhancing community resilience. European Journal of Psychotraumatology, 5(1), 1-10.

[9] Gibbs, S., \& Miller, A. (2013). Teachers' resilience and well-being: a role for educational psychology. Teachers and Teaching: Theory and Practice, 1-13. Doi: 10.1080/13540602.2013.844408

[10] Richards, J. (2012). Teacher stress and coping strategies: A national snapshot. The Educational Forum, 76, 299-316.

[11] Neff, K. D., \& Faso, D. J. (2015). Self-compassion and well-being in parents of children with autism. Mindfulness, 6(4), 938-947. https://doi.org/10.1007/s12671-0140359-2

[12] Yarnell, L. M., Stafford, R. E., Neff, K. D., Reilly, E. D., Knox, M. C., \& Mullarkey, M. (2015). Meta-analysis of gender differences in self-compassion. Self and Identity, 14(5), 499-520. https://doi.org/10.1080/15298868.2015.1029966.

[13] Bluth, K., Mullarkey, M., \& Lathren, C. (2018). Self-compassion: A potential path to adolescent resilience and positive exploration. Journal of Child and Family Studies, 27(9), 3037-3047. https://doi.org/10.1007/s10826-018-1125-1.

[14] Neff, K., \& Germer, C. (2013). A pilot study and randomized controlled trial of the mindful self-compassion program. Journal of Clinical Psychology, 69(1), 28-44. doi: 10.1002/jclp.21923.

[15] Balgiu, B. (2017). Self-esteem, personality and resilience. Study of a students emerging adults group. Journal of Educational Sciences and Psychology, 7(1), 93-99.

[16] Yang, C., Zhou, Y., Cao, Q., \& Xia, M. (2019). The relationship between self-control and self-efficacy among patients with substance use disorders: Resilience and selfesteem as mediators. Front Psychiatry, 10, 388. DOI: 10.3389/fpsyt.2019.00388.

[17] Karatas, Z., Ersoy, M. A., \& Cakar, F. S. (2011). Self-esteem and hopelessness, and resiliency: An exploratory study of adolescents in Turkey. International Education Studies, 4(4), 84-91. DOI:10.5539/ies.v4n4p84. 
[18] Reivich, K., \& Shatte, A. (2003). The resilience factor: 7 Keys to finding your inner strength and overcoming life's hurdles. New York: Broadway.

[19] Arslan, G. (2019). Mediating role of the self-esteem and resilience in the association between social exclusion and life satisfaction among adolescents. Personality and Individual Differences, 151, 109514. DOI: https://doi.org/10.1016/j.paid.2019.109514. 